\title{
High Conversion Ratio Converter Using Half-Bridge Sub-Modules
}

\author{
Shalini Roy ${ }^{1}$, Rahul Pandey ${ }^{2}$ \\ ${ }^{1}$ Shalini Roy, M.Tech Student, Shri Shankracharaya Group of Institutions, Bhilai, India. \\ ${ }^{2}$ Rahul Pandey, Assistant Professor, Shri Shankracharaya Group of Institutions, Bhilai, India. \\ ${ }^{1}$ shaliniroy602@gmail.com \\ 2raahul117@gmail.com
}

\begin{abstract}
An appreciable and significant assess of consideration and mindset is currently growing up for power dc-dc converters and its further more consideration is taken towards adoption of Modular-Multilevel Converters (MMC). The paper presents a transformer less MMC by the means of superior and advanced conversion ratio for higher dc-dc power conversion. This converter is being capable of utilized mutually for both the Medium Voltage Direct Current (MVDC) transmission systems and High Voltage Direct Current (HVDC) transmission systems, due to its some remarkable distinctive attributes such as modular design, scalability, consistency, tolerance of failures, larger step up and step down ratio and lowers filtering requirements. The MMC idea connects $\mathbf{N}$ low voltage sub-modules in sequence to produce a high voltage output. Thus there is no complex control algorithm necessary to stabilize or balance the voltages in every sub-module. Thus the simulation and analysis of a MMC design connected with stray inductances in order to reduce losses is done with an instance of 11-times stepping up ratio.
\end{abstract}

Keywords - Modular Multilevel Converters (MMC), electronic power conversion, reliability.

\section{INTRODUCTION}

Recently, Modular Multilevel Converters (MMCs) application and examination has rapidly gone into complete swing over the past few years. With the expansion and enlargement of MVDC and HVDC technology, many of the current dc-dc power conversion systems can be constructed by means of power conversion techniques in order to simplify and ease up the step-up voltage and convert step-down voltage functionality [1-3]. However, the MMC idea offers the possibility of using the dc-dc converter in MVDC or HVDC scheme, such as in urban power distribution system, electric vehicles, traction system, electric ships etc. Thus MMC is getting more and more popularized and effective in recent years [5-11].

Even though MMC technologies are previously established to study advanced and verified features of converters in addition to auxiliary difficulties energy effectiveness, consistency, power compactness, simplicity, price minimization with expanding their field of implementation to develop into more appealing and competitive topology [4-10]. Numerous multilevel dc-dc converters are suggested excluding magnetic parts in order to obtain elevated effectiveness and high power density. Thus it ensures high peak conversion ratio thereby restricting large power losses [12-14].

Furthermore additional promising dc-dc power conversion techniques which would deliver an elevated voltage conversion ratio include Switched Capacitor and Dual Active Bridge Modular Multilevel. Various Switched Capacitor techniques use stray inductance to accomplish Zero Current Switching operation [15-16]. The use of stray inductances helps to reduce the high voltage and current spikes that are generated by switching devices. In addition to Switched Capacitor technique the Dual Active Bridge Modular Multilevel techniques are more efficient and upcoming source of medium and high voltage application by utilizing MMC. Modular Multilevel Dual Active Bridge (DAB) through Input Series Output Series (ISOS) configuration can be also featured for elevated voltage dcdc power conversion.

This paper introduces an innovative performance method for generating high DC voltage with the suggested MMC topology with small DC voltage supply [17-19]. The benefits and advantages of the suggested converter topology are as follows:

1. The automatic manipulation of voltage sharing by the different converter topologies.

2. The computation burden is dramatically reduced.

3. Its higher efficiency, which is marked as an important priority for high-power application.

4. With the amount of levels engaged, the difficulty and complications does not improve significantly.

5. The power losses and filtering needs are greatly reduced.

6. Small sizes of passive components are used and thus it does not require additional large size inductor for balancing. 


\section{International Journal of Engineering Technology and Management Sciences[IJETVIS]}

Website: ijetms.in Issue:5, Volume No.4, September-2020 DOI: 10.46647/ijetms.2020.v04i05.020

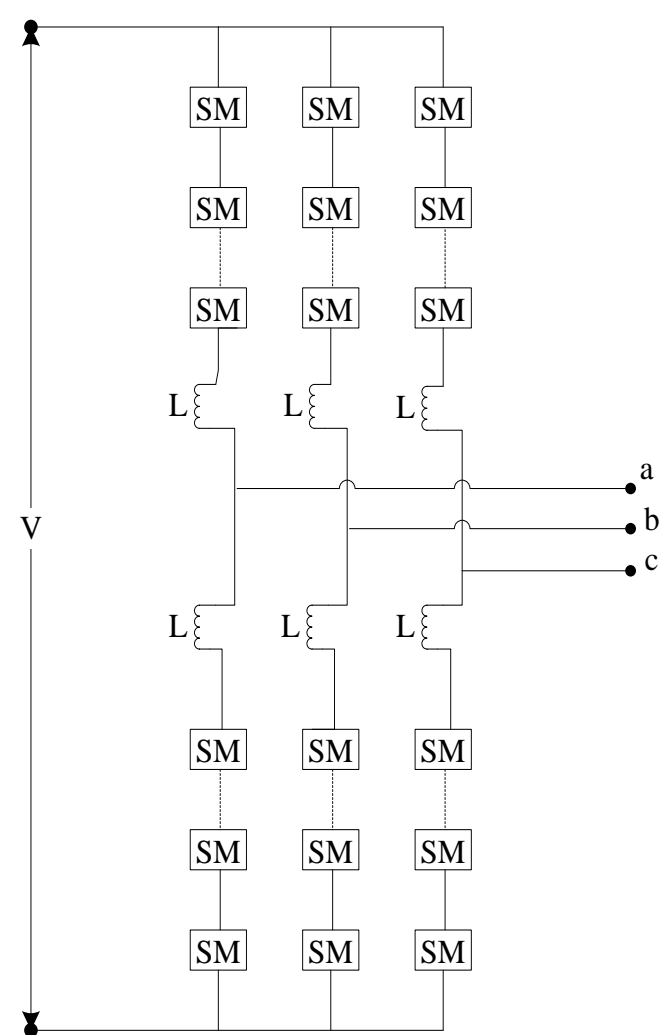

Fig1. Basic Configuration of MMC

\section{MMC BASED DC-DC CONVERTERS}

The novel MMC based dc-dc converter topology have been intensively studied and developed, appreciating many characteristics such as strong modularity, easy scalability, reduced or minimized filter cost, robust control, easy configuration structure, idleness and redundancy. The difficulties, problems and drawbacks of Dual Active Bridge Converter can be avoided by the means of utilizing modular multilevel converter. This type of converter consists of identical energy cells linked in the sequence as represented in fig1, in addition to it every cell of converter consists of typical standard components, allowing the link to high voltages pole. The modular design of MMC's allows to wider the range of high voltage rates at the same time ensuring identical and homogeneous stress taking place on the systems of semiconductors. The MMC is an extremely well organized and efficient converter by means of elevated power efficiencies of up to $99.5 \%$. The MMC based DC-DC converter is recommended with elasticity and adjustable expansion of reduced harmonics followed by fault isolation. They can be flexibly connected to various operating states, particularly in case of the HVDC transmission power grid.

\section{PROPOSED CONVERTER TOPOLOGY AND ITS OPERATION}

Moreover fundamental structural design of the proposed circuit topology for the MMC with different submodule is as shown in fig2. The working principle and control of the system is established with analysis of system performance.

\section{A. System Topology and Sub-Module Configuration}

The structural arrangement of the proposed converter topology consist of series connection of the $\mathrm{N}$ number of sub-modules (SMs) with single inductor (L), constructing the two arms of the converter and utilizing a one individual dc source for the converter as shown in fig2. In order to elevated dc voltage on the output arm, each of individual sub-modules has a small dc voltage. The number of submodules designated depends on the power capacity and applications which will be employed. Multiple connections of capacitors are done with each of the sub modules which results in form of minute current flow from the capacitor and reduced losses. The stray inductances used in each submodule also helps to achieve Zero Current Switching operation even when the capacitor are bypassed and thus minimizes the high voltage and current spikes generated by the switching devices of the converter.

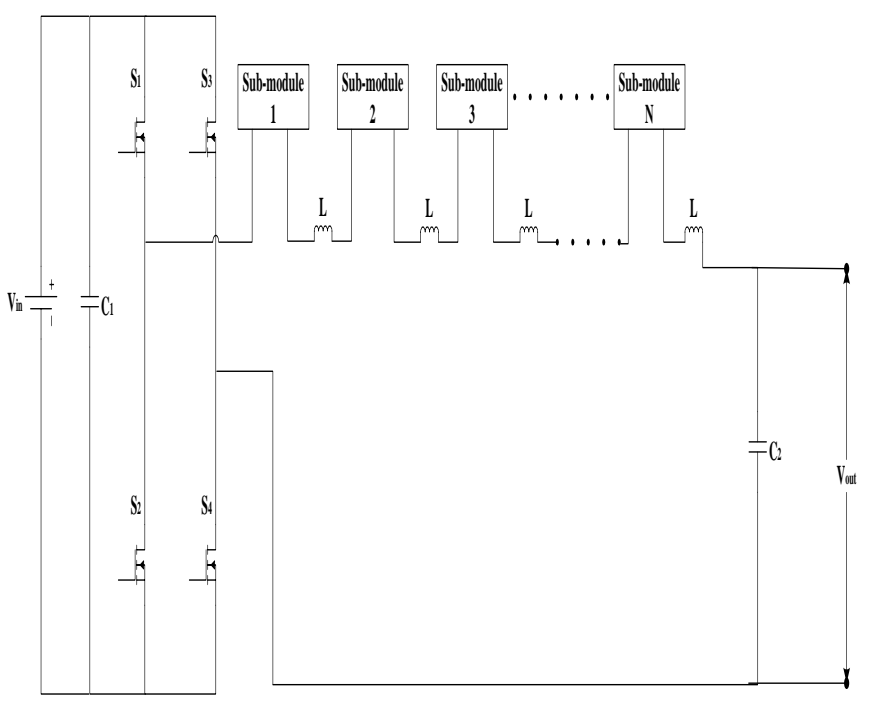

Fig2. Basic Structure of Modular Multilevel Converter

\section{B. Control of Proposed Converter}

The projected converter topology with six half bridge sub-modules (HB-SM) is represented in fig3. In order to accomplish and attain elevated power conversion ratio, only individual sub-module will be disabled at a time, which means only single capacitor will be bypassed throughout the entire operating sequence. The suggested 


\section{International Journal of Engineering Technology and Management Sciences[IJETMIS]}

Website: ijetms.in Issue:5, Volume No.4, September-2020 DOI: 10.46647/ijetms.2020.v04i05.020

converter topology is controlled by utilizing phase-shifted PWM control method. The phase shifted based PWM technique can easily overcome all the lower order harmonics for the multilevel converters. On the other hand in the conventional phase shifted technique, each carrier correlates to the switching cycle of individual sub-modules. In this method, each of the MMC sub modules individually and separately regulated. The PWM signals for each of the sub-module of the converter enclosed and has been divided into six equal parts and is shifted through angle of $0 \circ, 60^{\circ}$, $120^{\circ}, 180^{\circ}, 240^{\circ}$ and $300^{\circ}$ respectively.

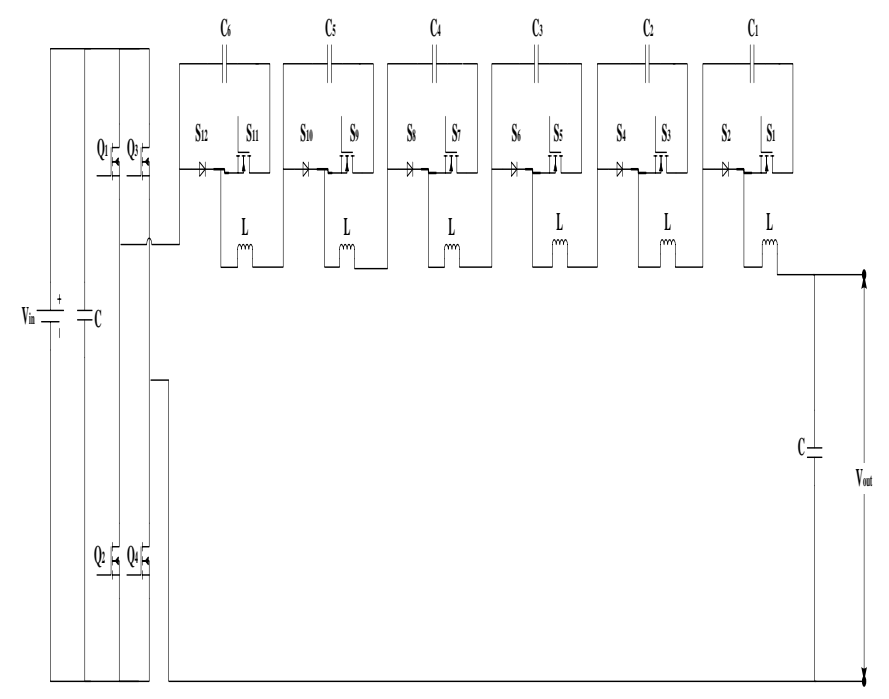

Fig3. Proposed Converter Topology

\section{General Considerations and System Assessment}

The assessment of proposed topology of Modular Multilevel DC-DC Converter is done with subsequent assumptions as determined below:

1. The switching systems of the converter are ideal.

2. In every sub-module, the parameters of all components are identical.

3. There is refusal of dead time to the converter's function.

4. The fluctuation in the capacitor voltage should be ignored.

The switching frequencies of the entire sub-modules switches would be similar and identical while the converter is working in steady condition. As per the above considerations, the standard voltage is presumed to be identical transversely across each and every capacitor. The converter operation takes place in two equivalent mode i.e. mode1 and mode2.
Mode1: In mode1 of converter operation all the upper switching devices of each and every sub-module are turned ON. The voltages across each of the sub module in mode1 can be calculated as follows

$$
V_{S M}=V_{C i}+V_{L}
$$

were $\mathrm{i}=1,2, \ldots, 6$

The relation connecting the input voltage and output voltage in this mode can be given by the equation

$$
V_{\text {out }}=6 V_{C i}+6 V_{L}-V_{\text {in }}
$$

Mode2: In mode2 of converter operation the switch S1 is boot out and the switch S2 is boot in, and thus the submodule consisting of capacitor $\mathrm{C} 1$ is deactivated. Therefore the relation between the input voltage and output voltage in this mode can be given by the equation

$$
V_{\text {out }}=5 V_{C i}+V_{\text {in }}
$$

were $\mathrm{i}=1,2, \ldots, 6$

Consequently the average output voltage can be calculated as

$$
V_{\text {out }}=\frac{2 *(6-1) * V_{C i}}{2}
$$

\section{Voltage Balancing of Sub-Modules}

The major and foremost benefit of the proposed converter is self voltage balancing ability across the converter sub-module. Same as the variety of different multilevel converter topologies MMCs also have requirement of maintaining a balance of voltages around the sub-module. Hence advancement and expansion within the features of MMC includes the sub-module capacitor voltage balancing in it. This characteristic draws advantages from reduced converter voltage and current losses, simpler hardware structure along with reduced price. It also improves the reliability of the converter. According to the previous analysis it has been observed that the sub-module capacitors are constantly linked and attached in series along the activated sub-module. Thus each and every single capacitor tends to contribute high voltages across through an identical and equivalent voltage scheduled on all capacitors. As per the end result, the entire sub-module capacitor is automatically balanced.

\section{E. Comparison of Proposed Converter with Other Converters}

The comparison between the proposed modular multilevel converter and other modular multilevel 


\section{International Journal of Engineering Technology and Management Sciences[IJETMIS]}

Website: ijetms.in Issue:5, Volume No.4, September-2020 DOI: 10.46647/ijetms.2020.v04i05.020

converter is presented in Table I. It has been seen that the proposed converter has the same higher and acceptable voltage gain as that of the modular converter presented in [1]. The converter in [1] has sets of MOSFET as the switching element in its sub-modules were as the proposed converter has sets of diode and MOSFET connected along with stray inductance in its sub-modules for the $\mathrm{N}$ number of stages. From the point of view of number of elements the proposed converter has one diode as a switching element replacing the MOSFET in the sub-modules. Thus it can be noted that the proposed converter has the same voltage gain with high efficiency and reduced losses with less number of elements at lower cost and minimal size.

Table1: Comparison of the proposed converter with other converter

$\begin{array}{lcl}\text { Parameter } & \text { Proposed Converter } & \text { Presented in [1] } \\ \text { Sub-module number } & 6 & 6 \\ \text { Diode } & 6 & 0 \\ \text { MOSFET } & 6 & 12 \\ \text { Input Voltage } & 600 \mathrm{~V} & 600 \mathrm{~V} \\ \text { Output Voltage } & 6600 \mathrm{~V} & 6600 \mathrm{~V} \\ \text { Duty Cycle } & 0.913 & 0.913 \\ \text { Efficiency } & \text { High } & \text { High }\end{array}$

\section{SIMULATION RESULT}

The idea of proposed version of half-bridge MMC was being verified by using MATLAB simulation. The simulation is also done to validate and justify the purpose of converter by the means of half bridge sub-module. In order to attain a higher conversion ratio the proposed converter is operating under phase shift PWM control technique. As shown in fig4 the PWM signal for every submodule is been shifted through an angle of $0 \circ, 60^{\circ}, 120^{\circ}$, $180^{\circ}, 240^{\circ}$ and $300^{\circ}$ respectively.

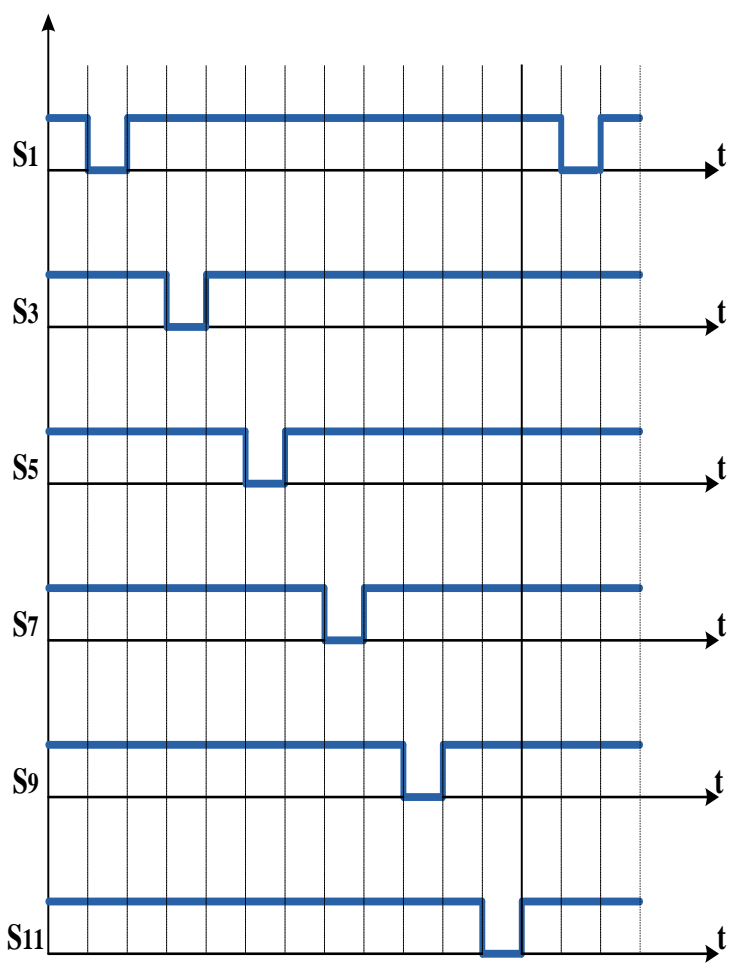

Fig4: Phase-shifted PWM waveform

The simulation end result of the proposed MMC converter consisting of six half bridge sub-modules is shown in fig5 and fig6. The suggested half bridge submodule converter produces 11times step-up voltage i.e. producing a voltage of $6.6 \mathrm{kV} \mathrm{dc}$ on the output terminal, with an average standard capacitor voltage of $1.2 \mathrm{kV}$. And thus the voltage across each and every sub-module capacitor is equally balanced.

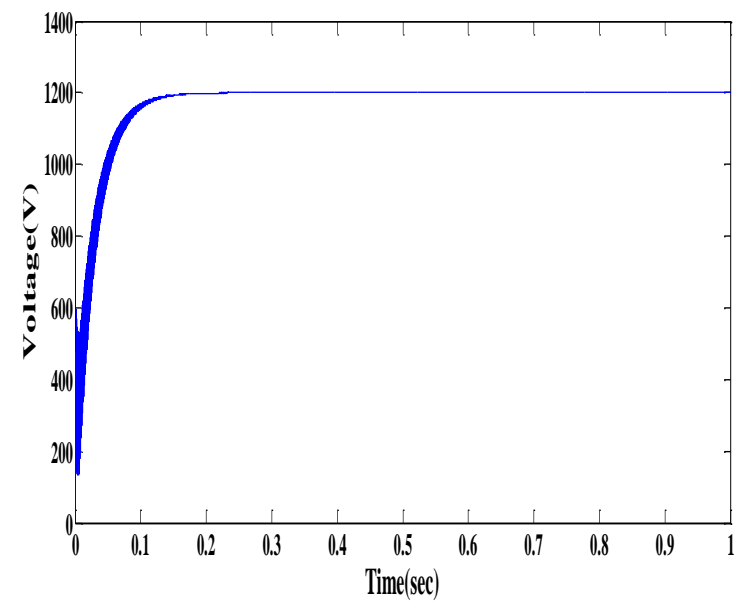

Fig5: Capacitor voltage waveform 
Website: ijetms.in Issue:5, Volume No.4, September-2020 DOI: 10.46647/ijetms.2020.v04i05.020

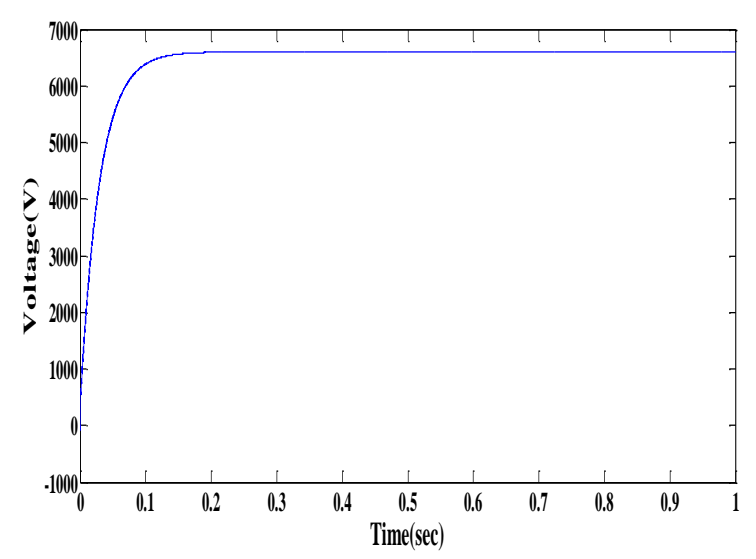

Fig6: Output voltage waveform

\section{CONCLUSION}

This paper introduces an unmarked and new transformer less dc-dc MMC with phase shifted PWM control method applied to converter operation, as more and more individuals become involved by adapting and paying attention towards prominent and superior conversion ratio dc-dc modular multilevel converters. The converter proposed in this paper uses the stray inductance, by assembling the recommended converter as inductor less converter. In addition, every sub-modules modular design made it incredibly and extremely simple to preserve this converter. This gives advantages from lower price, elevated effectiveness, higher density of energy and larger reliability. Moreover, the malfunctioned sub-module is capable of being bypassed by utilizing the arrangement of redundant sub-module, which enables the converter to comprise of elevated tolerance capabilities. The simulation outcome demonstrates that the converter with reduced number of switches along with decreased standard device switching frequency and decreased switching losses the elevated and superior conversion ratio can be attained.

\section{References}

[1] Yanchao Li, Xiaofeng Lyu, and Dong Cao, "A Zero-CurrentSwitching High Conversion Ratio Modular Multilevel DC-DC Converter", IEEE Journal of Emerging and Selected Topics in Power Electronics Vol. 5(1), pp. 151-161, October 2017.

[2] Shalini Roy, Rahul Pandey, "Modular Multilevel DC-DC Converters: A Review", i-manager's Journal on Electrical Engineering, ISSN: 2230-7176, Vol. 13(1), July- September 2019.

[3] Rahul Pandey, Lalit Kumar Sahu, Saji T. Chacko, "Self-balanced Modular Multilevel DC-DC converter for High Conversion Ratio". First International Conference on Power, Control and Computing Technologies (ICPC2T), DOI: 10.1109/ ICPC2T48082.2020.9071479, 3-5 January 2020.

[4] Sonal Purkait, Rahul Pandey, "Brief Introduction to Modular Multilevel Converters and Relative Concepts and Functionalities",
Journal of i-Manager's Journal on Digital Signal Processing, ISSN Print: 2321-7480, ISSN Online: 2322-0368, 2019.

[5] Sonal Purkait, Rahul Pandey, "Modular Multilevel Converters an Overview: Basic Concepts, Design and Control along with Applications", International Journal of Emerging Technologies and Innovative Research JETIR, Vol. 5(7), pp.835-843, July-2018.

[6] Sonal Purkait, Rahul Pandey, Lalit kumar Sahu and Saji.T.Chacko, "Design of High Step-Up Transformer-less Modular Multilevel DC-DC Converter", Book: Advances in Intelligent Systems and Computing, Vol. 989, Pages 163-173ISBN: 978-98113-8617-6, , Springer 2018.

[7] J. A. Ferreira, "The Multilevel Modular DC Converter", IEEE Transactions on Power Electronics, Vol. 28, pp. 4460-4465, October 2013.

[8] Suman Debnath, Jiangchao Qin, Behrooz Bahrani, Maryam Saeedifard, and Peter Barbosa. "Operation, Control, and Applications of the Modular Multilevel Converter: A Review", IEEE transactions on Power Electronics, Vol.30, no.1, June 2015.

[9] B. Li, S. Zhou, D. Xu, S. J. Finney, and B. W. William. "A hybrid modular multi-level converter for medium-voltage variable-speed motor drives", IEEE Transactions on Power Electronics, Vol.32, pp.4619-4630, June 2017.

[10] Hongvheng You and Xu Cai, "A Three-Level Modular DC/DC Converter Applied in High Voltage DC Grid", IEEE Access, Vol.6, pp. 25448-25462, April 2018.

[11] S. Kenzelmann, A. Rufer, D. Dujic, F. Canales, and Y. R. De Novaes, "Isolated DC/DC Structure Based on Modular Multilevel Converter", IEEE Transactions on Power Electronics, Vol. 30, pp. 89-98, October 2015.

[12] Seema Mir Akbar and Ammar Hasan, "Review of High Voltage DC/DC Modular Multilevel Converters", International Conference on Smart Cities: Improving Quality of Life Using ICT \& IoT (HONET-ICT), Islamabad, Pakistan, May 2018.

[13] I. A. Gowaid, G. P. Adam, S. Ahmed, D. Holliday, and B. W. Williams, "Analysis and Design of a Modular Multilevel Converter With Trapezoidal Modulation for Medium and High Voltage DC-DC Transformers", IEEE Transactions on Power Electronics, Vol. 30(10), pp. 5439-5457, October 2015.

[14] R. Darus, G. Konstantinou, J. Pou, S. Ceballos, and V. G. Agelidis, "Comparison of Phase-Shifted and Level-Shifted PWM in the Modular Multilevel Converter", IEEE International Conference on Power Electronics Hiroshima, Japan, pp. 3764-3770, February 2014.

[15] Qiang Ren, Chi Sun, and Fei Xiao, "A Modular Multilevel DC-DC Converter Topology with a Wide Range of Output Voltage", IEEE Transactions on Power Electronics Vol. 32(8), July 2017.

[16] Stefan P. Engel, Marco Stieneker, Nils Soltau, Sedigheh Rabiee, Hanno Stagge, and Rik W. De Doncker, "Comparison of the Modular Multilevel DC Converter and the Dual-Active Bridge Converter for Power Conversion in HVDC and MVDC Grids", IEEE Transactions on Power Electronics, Vol. 30, January 2015.

[17] J.Mei, K.Shen, B.Xiao, L.Tolbert, and J.Zheng. "A new selective loop bias mapping phase disposition PWM with dynamic voltage balance capability for modular multilevel converter", IEEE Transactions on Indrustrial Electronics, Vol. 61(2), pp. 798-807, March 2013.

[18] J. Wang, R. Burgos, and D. Boroyevich, "Switching Cycle Capacitor Voltage Control for the Modular Multilevel DC / DC Converters", IEEE Applied Power Electronics Conference and Exposition (APEC), Charlotte, NC, USA, pp. 377-384, March 2015. 
Website: ijetms.in Issue:5, Volume No.4, September-2020 DOI: 10.46647/ijetms.2020.v04i05.020

[19] Madicheety Sreedhar, Abhijit Dasgupta and Sambeet Mishra. "New Harmonic Mitigation Scheme for modular Multilevel Converter- An Experimental Approach",IET Power Electronics, Vol. 7(12), pp. 3090-3100, July 2014.

[20] Estíbaliz Solas, Gonzalo Abad, Jon Andoni Barrena, Sergio Aurtenetxea, Ainhoa Carcar, and Ludwik Zajac. "Modular Multilevel Converter with Different Submodule ConceptsPart I: Capacitor Voltage Balancing Method", IEEE Transactions on Industrial Electronics, Vol. 60(10), pp.4525-4535, October 2013.

[21] Estíbaliz Solas, Gonzalo Abad, Jon Andoni Barrena, Sergio Aurtenetxea, Ainhoa Carcar, and Ludwik Zajac. "Modular Multilevel Converter With Different Submodule ConceptsPart II: Experimental Validation and Comparison for HVDC Application", IEEE Transactions on Industrial Electronics, Vol. 60(10), pp.45364545, October 2013.

[22] Hao Peng, Rui Xie, Kun Wang, Yan Deng, Xiangning He,and Rongxiang Zhao. "A Capacitor Voltage Balancing Method with Fundamental Sorting Frequency for Modular Multilevel Converters under Staircase Modulation", IEEE Transactions on Power Electronics, Vol.31, pp.7809-7822, November 2016.

[23] Monirul Islam, Saad Mekhilef, and Mahamudul Hasan. "Single phase transformer less inverter topologies for grid-tied photovoltaic system: A Review", Renewable and Sustainable Energy Reviews, Vol.45, pp.69-86, January 2015.

[24] B. Li, S. Zhou, D. Xu, S. J. Finney, and B. W. Williams. "A hybrid modular multi-level converter for medium-voltage variable-speed motor drives", IEEE Transactions on Power Electronics, Vol.32, pp.4619-4630, June 2017.

[25] S. Kouro, J. Rodriguez, B. Wu, S. Bernet, and M. Perez. "Powering the future of Industry: High-power adjustable speed drive topologies", IEEE Indrustry Applications Magazine, Vol. 18, no. 4, pp. 26-39, August 2012.

[26] Yuvaraja, T., and Somnath Mazumder. "Performance and Analysis of Modular Multilevel Converter", American Journal of Engineering Research (AJER), Vol.3, pp. 2320-0936, 2014.

[27] S.Da, A'ZArco, L.Piegari, M.S.Quraan, and P.Tricoli. "Battery charging or electric vehicles with modular multilevel traction drives", In 7th IET International Conference on Power Electronics, Machines and Drives pp. 1-6, 2014.

[28] M. Quraan, P. Tricoli, S. D.Arco, and L. Piegari. "Efficiency assessment of modular multilevel converters for battery electric vehicles." IEEE Transactions on Power Electronics, Vol.32, pp. 2041-2051, March 2017.

[29] B. Li, S. Zhou, D. Xu, S. J. Finney, and B. W. William. "A hybrid modular multi-level converter for medium-voltage variable-speed motor drives", IEEE Transactions on Power Electronics, Vol.32, pp.4619-4630, June 2017.

[30] Du, S.; Liu, J. “A Study on DC Voltage Control for Chopper-CellBased Modular Multilevel Converters in D-STATCOM Application", IEEE Transaction on Power Delivery Vol. 28, pp. 2030-2038, October 2013.

[31] Mohammadi, P.H.; Bina, M.T. “A Transformer less MediumVoltage STATCOM Topology Based on Extended Modular Multilevel Converters.", IEEE Transaction on Power Electronics, Vol.26, pp.1534-1545, May 2011. 